\title{
A 45-year-old woman with a pre-sacral mass lesion
}

\author{
Inderjeet Nagra • Alistair J. Stirling • Steven L. J. James
}

Published online: 21 November 2009

(C) ISS 2009

\begin{abstract}
A 45-year-old woman presented with a 3-year history of intermittent episodes of low back pain associated with leftsided sciatica. This had progressed over the past 18 months and the pain was now radiating to her toes, causing difficulty with walking. Clinical examination was normal and initial investigations including routine blood tests and radiographs of the lumbosacral spine were unremarkable. Her past medical history included rectal carcinoma,
\end{abstract}

previous hysterectomy and bilateral oophorectomy, asthma and hyperthyroidism. MRI of the lumbar spine (not shown) and sacrum was performed including sagittal T1-weighted (Fig. 1a), sagittal T2-weighted (Fig. 1b), axial T2-weighted (Fig. 1c), axial fat-suppressed T1-weighted images pre- and post-gadolinium administration (Fig. 1d, e). A trans-sacral CT-guided biopsy was performed, the histology of which is illustrated in Fig. 2.

The diagnosis can be found at doi:10.1007/s00256-009-0832-5

I. Nagra $\cdot$ S. L. J. James $(\bowtie)$

Department of Radiology, The Royal Orthopaedic Hospital NHS

Foundation Trust,

Birmingham B31 2AP, UK

e-mail: steven.james@roh.nhs.uk

\section{A. J. Stirling}

Department of Spinal Surgery, The Royal Orthopaedic Hospital

NHS Foundation Trust,

Birmingham B31 2AP, UK 

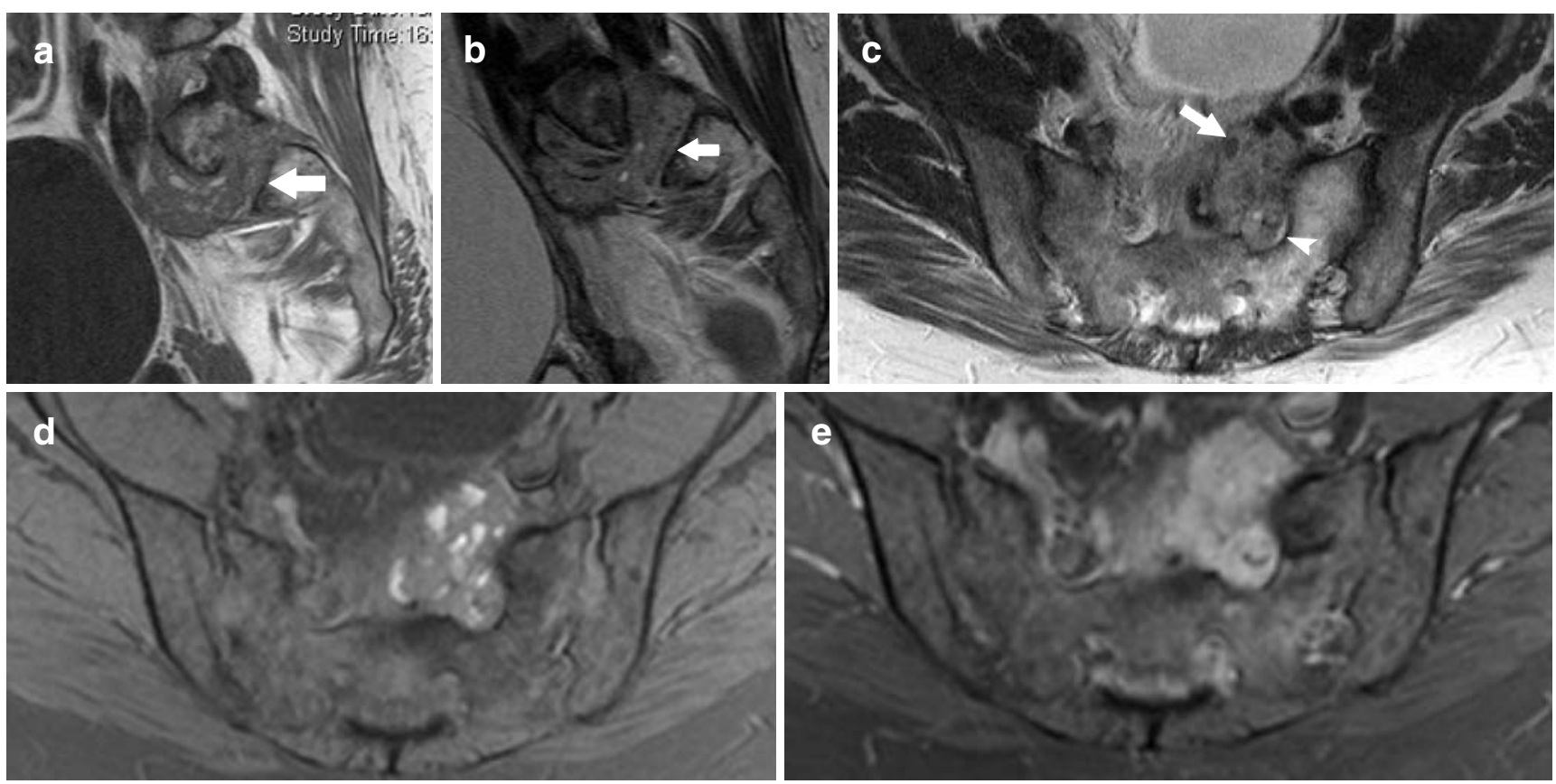

Fig. 1 MRI of the sacrum (arrows) included a sagittal T1-weighted, b sagittal T2-weighted, $\mathbf{c}$ axial T2-weighted, d, e axial fat-suppressed T1weighted images pre- (d) and post-gadolinium (e) administration

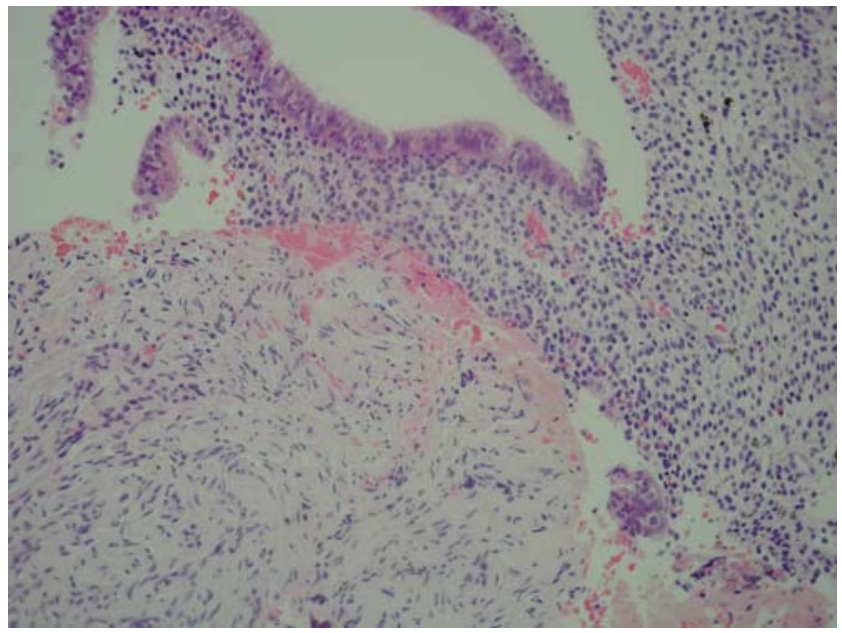

Fig. 2 Histopathology image of the CT-guided biopsy material $(\mathrm{H} \& \mathrm{E})$ 